\title{
Quorum-Sensing Systems in the Plant Growth-Promoting Bacterium Paraburkholderia phytofirmans PsJN Exhibit Cross-Regulation and Are Involved in Biofilm Formation
}

\author{
Ana Zúñiga, Raúl A. Donoso, Daniela Ruiz, Gonzalo A. Ruz, and Bernardo González \\ Facultad de Ingeniería y Ciencias, Universidad Adolfo Ibáñez, Millennium Nucleus Center for Plant Systems and Synthetic \\ Biology, and Center of Applied Ecology and Sustainability (CAPES), Santiago, Chile
}

Accepted 4 April 2017.

\begin{abstract}
Quorum-sensing systems play important roles in host colonization and host establishment of Burkholderiales species. Beneficial Paraburkholderia species share a conserved quorumsensing (QS) system, designated BraI/R, that controls different phenotypes. In this context, the plant growth-promoting bacterium Paraburkholderia phytofirmans PsJN possesses two different homoserine lactone QS systems BpI.1/R.1 and BpI.2/R.2 (BraI/R-like QS system). The BpI.1/R.1 QS system was previously reported to be important to colonize and produce beneficial effects in Arabidopsis thaliana plants. Here, we analyzed the temporal variations of the QS gene transcript levels in the wild-type strain colonizing plant roots. The gene expression patterns showed relevant differences in both QS systems compared with the wild-type strain in the unplanted control treatment. The gene expression data were used to reconstruct a regulatory network model of QS systems in $P$. phytofirmans PsJN, using a Boolean network model. Also, we examined the phenotypic traits and transcript levels of genes involved in QS systems, using $P$. phytofirmans mutants in homoserine lactone synthases genes. We observed that the BpI.1/R.1 QS system regulates biofilm formation production in strain PsJN and this phenotype was associated with the lower expression of a specific extracytoplasmic function sigma factor ecf26.1 gene (implicated in biofilm formation) in the bpI.1 mutant strain.
\end{abstract}

The nutrient-rich rhizosphere is essential for plantmicroorganism associations, since plant exudates enrich the soil material in close contact with plant roots and, therefore, contain much larger microbial numbers and activities than the nonrooted bulk soil; thus, it is from the rhizosphere that microbes are recruited to play some benefitial or pathogenic functions in plants (Bakker et al. 2013). Plant growthpromoting bacteria (PGPB) are one of the best-studied groups of beneficial bacteria because of their increasing agronomic importance. PGPB are able to colonize root surfaces, forming tight rhizospheric interactions and, occasionally, establishing endophytic populations (Dekkers et al. 1998; Idris et al. 2007; Lery et al. 2011). PGPB induce beneficial effects on plant

Corresponding author: B. González; Telephone: +1 56-2-23311619; Fax: +1 56-2-23311906; E-mail: bernardo.gonzalez@uai.cl

*The $\boldsymbol{e}$-Xtra logo stands for "electronic extra" and indicates that four supplementary figures and one supplementary table are published online.

(c) 2017 The American Phytopathological Society growth through several mechanisms, such as nitrogen fixation, improvement of nutrient absorption, phytohormone production, and increasing tolerance to biotic and abiotic stresses (Bhattacharyya and Jha 2012; Compant et al. 2008; Idris et al. 2007; LópezBucio et al. 2007; Lugtenberg and Kamilova 2009; Kraiser et al. 2011; Vejan et al. 2016; Zúñiga et al. 2013). Remarkably, key characterized genes involved in plant growthpromoting effects and plant colonization are regulated by quorum-sensing (QS) systems (Pérez-Montaño et al. 2013; Quiñones et al. 2005; Steindler et al. 2009; Walker et al. 2004; Zúñiga et al. 2013). It has been reported that QS systems regulate several bacterial functions in a cell density-dependent manner, such as exopolysacharide biosynthesis, motility, biofilm formation, and siderophore biosynthesis, among others (Chapalain et al. 2013; Fuqua and Greenberg 2002; Goo et al. 2015; Packiavathy et al. 2013; Pérez-Montaño et al. 2013), acting as a regulator of bacterial cooperation, thus rendering such bacteria social in nature (Darch et al. 2012; Diggle et al. 2007; Goo et al. 2015). In gram-negative bacteria, the $\mathrm{N}$-acylhomoserine lactone (AHL) signal molecules are frequently synthesized to communicate through QS (Whitehead et al. 2001) and plants are able to detect and respond to AHL signal (Hernández-Reyes et al. 2014; Ortíz-Castro et al. 2009; Teplitski et al. 2011). Studies of plant responses to AHLs demonstrated that these molecules affect plant functions such as transcriptional regulation, response to stress and hormones turnover (Hernández-Reyes et al. 2014; Mathesius et al. 2003). In addition, plants are able to take up AHLs in a process dependent on the length of their acyl chain, modifying the growth of roots and rosettes (Götz et al. 2007; Ortíz-Castro et al. 2008; von Rad et al. 2008).

In PGPB such as Pseudomonas aeruginosa PUPa3, QS mediated by AHL regulates rice growth promotion (Steindler et al. 2009), while some PGPBs defective in QS signaling are less effective in host colonization (Bauer and Mathesius 2004; Ortíz-Castro et al. 2009; Quiñones et al. 2005; Zúñiga et al. 2013). Because of differences in PGPB ecology and physiology, QS-dependent regulation is highly diverse between species and strains (Bertini et al. 2014; Goo et al. 2015; McAnulla et al. 2007; Ryu et al. 2013; Sánchez-Contreras et al. 2007). QS systems possess regulatory genetic networks whose study might take advantage of the use of system biology methods to model and understand the dynamic behavior of these complex genetic systems (Audretsch et al. 2013; Dallidis and Karafyllidis 2014).

The Burkholderia genus has been well-defined as a phenotypic, metabolic, and ecologically diverse bacteria, with its members inhabiting diverse niches (Coenye and Vandamme 
2003; Pérez-Pantoja et al. 2012; Suárez-Moreno et al. 2012). Despite the fact that several different members of the genus are not pathogens, the most comprehensive characterization of Burkholderia genus has been conducted on those strains that are opportunistic human pathogens (Seo et al. 2015; Valvano et al. 2005). A phylogenetic tree based on 16S rRNA gene sequences of over 80 Burkholderia species shows a noticeable division in two clades (Depoorter et al. 2016). One of these clades comprises more than 25 nonpathogenic species mainly characterized for their beneficial association with plants, most of them being described as PGPB (Caballero-Mellado et al. 2007; Suárez-Moreno et al. 2010, 2012). Recently, this group of Burkholderia species has been proposed as belonging to a separate genus, namely, Paraburkholderia (Sawana et al. 2014). Of the above-mentioned nonpathogenic cluster, 20 species share a conserved AHL-based QS system, designated BraI/R$\mathrm{saL} / \mathrm{BraR}_{\mathrm{kur}}$ because it was first reported in $P$. kururiensis (Suárez-Moreno et al. 2008). The BraI/RsaL/BraR ${ }_{\text {kur }}$ QS system responds to 3-oxo-C14-AHL, and it has a regulatory protein named RsaL that represses the transcription of the AHL synthase encoded by the braI gene (Suárez-Moreno et al. 2008). The Burkholderia cepacia complex (BCC) pathogenic species possess a QS system named CepI/CepR, which produces $\mathrm{N}$-octanoyl homoserine lactone (C8-AHL) and it is unrelated to the $\mathrm{BraI} / \mathrm{RsaL} / \mathrm{BraR}_{\mathrm{kur}} \mathrm{QS}$ system (Suárez-Moreno et al. 2008, 2010, 2012). To date, no evidence has been reported relating both QS systems in a hierarchical connection (Choudhary et al. 2013). In members of order Burkholderiales, these QS systems regulate important phenotypic traits, principally those involved in colonization and niche invasion, in both pathogenic and beneficial species (Choudhary et al. 2013; Gamage et al. 2011; Malott et al. 2005). Furthermore, to control the phenotypic characteristics already mentioned, QS systems are part of complex interactions with a network of regulators, among which a sigma factor has been involved in QS hierarchical control in some species of Paraburkholderia (Aguilar et al. 2003; Solis et al. 2006; Wongtrakoongate et al. 2012).

P. phytofirmans PsJN is a PGPB that establishes rhizospheric and endophytic colonization in different plants and produces positive effects in horticultural crops like tomato, potato, and grape (Compant et al. 2008; Fernandez et al. 2012; Theocharis et al. 2012). P. phytofirmans PsJN possesses a conserved BraI/RsaL/BraR QS system (named BpI.2/RsaL/BpR.2) and an additional QS system named BpI.1/BpR.1, present in only a few of the plant-beneficial environmental Paraburkholderia spp. (as in P. xenovorans, named XenI2/R2) (Coutinho et al. 2013). In a previous study, we reported that an AHL synthase BraI-like mutant of $P$. phytofirmans PsJN (designated bpI.2) was still able to promote growth of Arabidopsis thaliana (Zúñiga et al. 2013). Similar results in plant growth-promoting effects were obtained using two different cultivars of Zea mays inoculated with the PsJN bpI.2 mutant (Coutinho et al. 2013). We also reported that no growth promotion in A. thaliana plants was observed when they were inoculated with the strain PsJN AHL synthase $b p I .1$ mutant, which also exhibited significantly low root-colonization levels compared with the wild-type strain (Zúñiga et al. 2013). These findings indicate regulatory effects on unidentified genes and functions involved in colonization and plant-growth promotion by the BpI.1/R.1 QS system of $P$. phytofirmans PsJN. In this context, functions of the additional BpI.2/rsal/R.2 QS system remain unknown. Determination of the dynamic behavior and interplay of both P. phytofirmans PsJN QS systems may provide a way to control and improve beneficial associations with plants.

The purpose of this work was to describe the possible hierarchic structure of the QS genes networks and biofilm production control in $P$. phytofirmans PsJN when this bacterium is exposed to $A$. thaliana plant roots. We reported a crossregulation between both QS systems mediated principally by the BpR.1 and RsaL regulators and that these systems apparently control a sigma factor related to biofilm production. We also carried out a temporal study to understand and reconstruct the regulatory network of both QS systems using a Boolean network model, thus allowing us to propose a network regulation model for these two strain PsJN QS systems in the presence of $A$. thaliana plant roots.

\section{RESULTS}

\section{QS systems gene expression in $P$. phytofirmans PsJN in the presence of $A$. thaliana plant roots.}

To address the function of QS systems in the first steps of plant colonization and growth promotion, we evaluated the temporal expression profile of QS genes in the PsJN wild-type strain after its inoculation in A. thaliana roots, using a hydroponic system of growth (Supplementary Fig. S1). We observed important differences between unplanted (control) and planted conditions in transcript levels of the five QS genes tested (Fig. 1). $b p I .1$ and $b p R .1$ gene transcript levels presented significant differences at 24 and $48 \mathrm{~h}$ after inoculation (Fig. 1). Transcript levels of both genes seem to be equally regulated in the unplanted control treatment but are differently regulated after $1 \mathrm{~h}$ of the exposure to the plant (Fig. 1), while the $b p R .1$ gene appears to be repressed in planted conditions or induced in unplanted conditions. Clear differences were also observed in $b p I .2$ and $b p R .2$ gene transcript levels at specific evaluated times in the PsJN strain, changing the pattern of expression observed in bacteria exposed to plant roots versus control treatment. $b p I .2$ gene transcript levels appear to be downregulated after 30 min postinoculation in medium with growing plants in comparison with the control treatment (Fig. 1), whereas those transcripts from $b p R .2$ presented a significant burst at $24 \mathrm{~h}$ postinoculation (Fig. 1). rsaL transcript levels were similar in control and planted treatments (Fig. 1). In general, transcript levels of QS genes changed when bacteria were inoculated in medium with growing plants, indicating a specific response to plant presence, but their expression pattern is complex to predict. To gain more insight about interaction of QS systems in strain PsJN when exposed to the presence of A. thaliana roots, we used the expression pattern data of $b p I .1$, $b p R .1, b p I .2, b p R .2$, and $r s a L$ genes (transcript levels of genes from bacteria in the presence of plant roots) to reconstruct a QS network. Using the Boolean network as a mathematical tool, we predicted a graph (Fig. 2) on which nodes represent the genes, proteins, or signaling molecules and the edges are the interactions between the parts of the QS systems. We obtained a network in which the 3-OH-C8-AHL-BpR.1 complex would positively regulate $b p I .1$ and $b p R .1$ gene expression and repress bpI.2 and rsaL gene expression (Fig. 2). In turn, 3-oxo-C14AHL-BpR. 2 complex positively regulates $b p I .2$ and $b p R .1$ gene expression and represses $b p I .1$ and their own expression (Fig. 2 ). The network also indicates that $r s a L$ represses $b p I .2$ gene expression and positively regulates $b p R .2$ (Fig. 2).

\section{Transcript levels of QS systems regulatory genes in wild-type $P$. phytofirmans PsJN and QS mutants.}

To test the cross-regulation in the QS network predicted by the model, we evaluated transcript levels of QS system genes in wild-type strain $P$. phytofirmans PsJN and of homoserine lactone synthases (producer of AHLs) in strain PsJN mutants. $P$. phytofirmans PsJN QS system BpI.1/R.1 produces 3-OHC8-AHL and the BpI.2/RsaL/R.2 QS system generates predominantly 3-oxo-C14-AHL and 3-OH-C14-AHL (Choudhary 
et al. 2013; Coutinho et al. 2013). We had previously observed that PsJN mutant strains in the AHL-producing genes $b p I .1$ and $b p I .2$ generated significantly lower levels of 3-OH-C8-AHL, and the bpI.2 mutant did not synthesize 3-oxo-C14-AHL (Zúñiga et al. 2013), suggesting that these QS systems are not mutually regulating the synthesis of these signal molecules and that, possibly, these QS systems are not cross-regulated, contrary to what the QS network model predicted. To address this point, we determined the transcripts levels of the $b p R .1, b p R .2$, and $r s a L \mathrm{QS}$ regulatory genes, using the quantitative reverse transcription-polymerase chain reaction (qRT-PCR) technique. We evaluated strains that had inactivated $b p I .1, b p I .2$, or both $b p I .1$ and $b p I .2$ genes and compared them with the wild-type strain at stationary phase of growth (minimal medium), when the concentrations of AHL molecules were expected to be at their highest. We observed a $b p R .1$ gene transcript levels three times lower in the $b p I .1$ single and $b p I .1-b p I .2$ double mutants than transcript levels observed in the wild-type strain (Fig. 3A), indicating that the 3-OH-C8-AHL-BpR.1 complex probably autoregulates their own expression. This was also analyzed evaluating transcript levels of the $b p R .1$ gene in cells of the wild-type strain induced with 3-OH-C8-AHL and 3-oxo-C14AHL molecules at exponential growth phase, when the concentrations of AHL molecules were expected to be at their lowest, for $1 \mathrm{~h}$. We observed that $b p R .1$ gene transcript levels were up-regulated $(25 \times)$ in the presence of $3-\mathrm{OH}-\mathrm{C} 8$-AHL, as compared with noninduced transcript levels (Fig. 3B), supporting the idea that 3-OH-C8-AHL-BpR.1 complex autoregulates their own expression. In contrast, $b p R .2$ and $r s a L$ gene transcript levels were up-regulated in the $b p I .1-b p I .2$ double mutant strain compared with the wild-type strain (Fig. 3A) but were downregulated in the bpI.1 and bpI.2 single mutants, 10 and $200 \times$, respectively. No changes were observed in transcript levels of the $b p R .2$ gene when cells were induced with 3-OH-C8-AHL and 3-oxo-C14-AHL molecules (Fig. 3B), dismissing a direct regulation of this gene by either that 3-OH-C8-AHL-BpR.1 or 3oxo-C14-AHL-BpR.2 complex or both. In contrast, the rsaL gene was down-regulated in the presence of 3-OH-C8-AHL and up-regulated in presence of 3-oxo-C14-AHL compared with those of noninduced strain PSJN cells, indicating a possible direct regulation of this gene by 3-OH-C8-AHL-BpR.1 and 3-oxoC14-AHL-BpR.2 complexes. Additionally, we observed that the $b p I .1$ gene was induced with 3-OH-C8-AHL and the bpI.2 gene was induced by 3-oxo-C14-AHL, suggesting a direct regulation by 3-OH-C8-AHL-BpR.1 and 3-oxo-C14-AHL-BpR.2 complexes, respectively.

We also tested the promoter activities of $b p I .1, b p I .2$, and rsaL genes in Escherichia coli, induced with 3-OH-C8-AHL and 3-oxo-C14-AHL molecules, to determine a possible direct regulation by BpR.1 and BpR2 QS regulators on these promoters. We observed that 3-oxo-C14-AHL increased 20-fold the promoter activity of bpI.2 and rsaL genes (Fig. 3C), confirming a direct regulation by the 3-oxo-C14-AHL-BpR.2 complex. Moreover, the presence of 3-OH-C8-AHL produced a 10 -fold increase in the promoter activity of the bpI.2 gene, suggesting that BpR.2 is promiscuous and is able to respond to other AHL molecules. No activity was observed in the rsaL promoter in the presence of 3-OH-C8-AHL. No induction
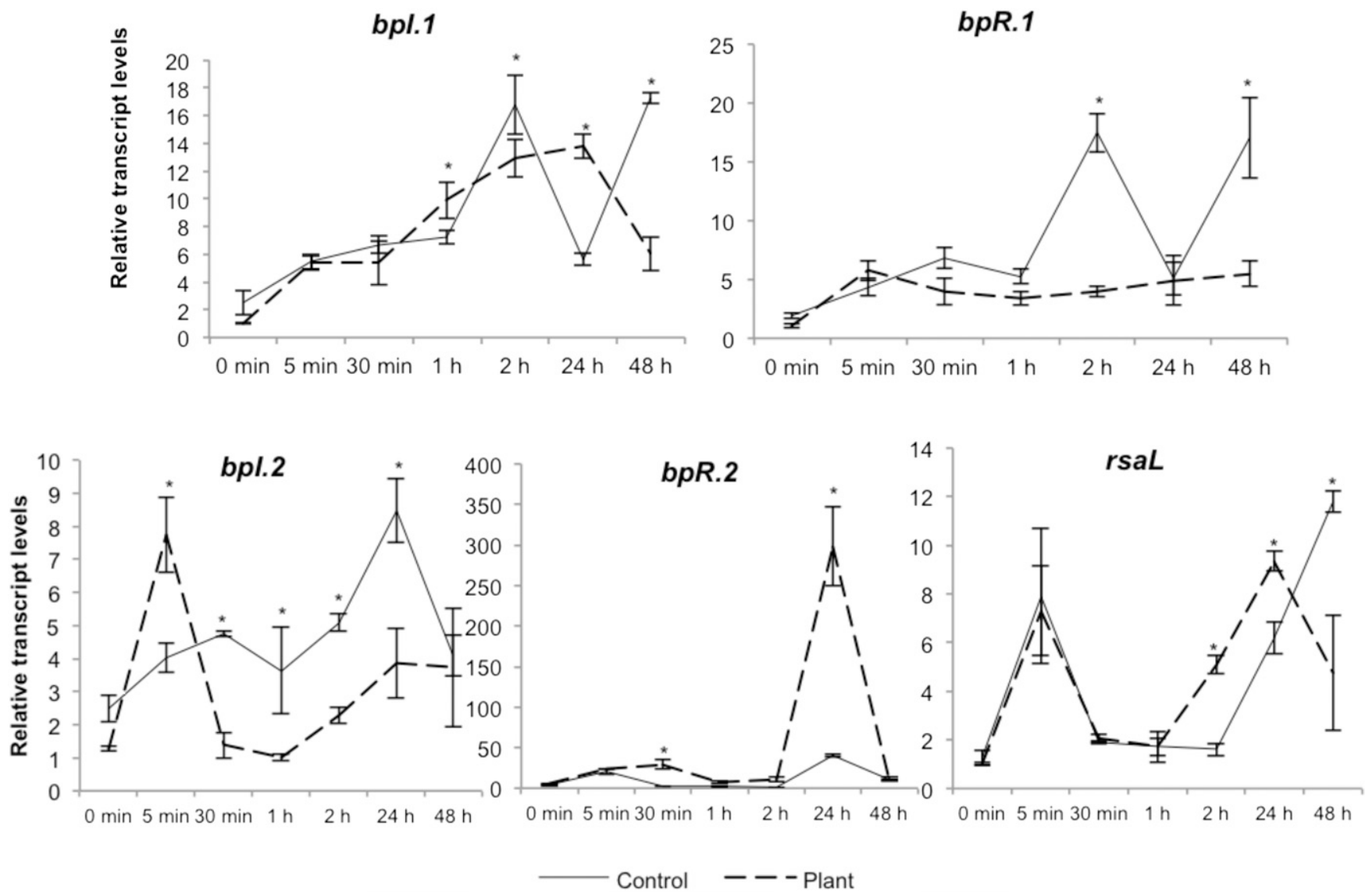

Fig. 1. Quorum-sensing system gene expression of Paraburkholderia phytofirmans PsJN in the presence of Arabidopsis thaliana roots. Quantitative reverse transcription-polymerase chain reaction determinations of relative transcript levels of the genes $b p I .1, b p I .2, b p R .1, b p R .2$, and $r s a L$ in the wild-type strain at 0,5 , and $30 \mathrm{~min}, 1,2,24$, and $48 \mathrm{~h}$ postinoculation. Data are means \pm standard errors of three biological replicates. Solid and dashed lines indicate the pattern expression of $P$. phytofirmans PsJN QS genes in hydroponic systems in the absence or the presence of the plant, respectively. Asterisks are used to indicate means that differ significantly (one-way analysis of variance significant difference tests, $P<0.05$ ). 
activity was observed in the $b p I .1$ promoter in the presence of 3-OH-C8-AHL or 3-oxo-C14-AHL molecules. These results indicate that the $3-\mathrm{OH}-\mathrm{C} 8$-AHL-BpR.1 complex regulator is not able to autoactivate $b p I .1$ promoter. This was confirmed by evaluating the activation of the $\mathrm{P}_{\text {bpl. }}$ promoter, using the same construction assessed in E. coli but in the presence of AHL obtained from spent supernatants of PsJN wild-type strain, as inducer, in which $\mathrm{P}_{\text {bpI. }}$ promoter displayed low activities but significantly higher as compared with control treatment induced with ethyl acetate (Supplementary Fig. S2). Additionally, we confirmed the activation of the $\mathrm{P}_{\text {bpI. }}$ promoter in $P$. phytofirmans PsJN wild-type strain, in which its activation was 10 -fold greater at the stationary phase of growth (optical density $[O D]=1.5)$ than in the exponential phase of growth $(\mathrm{OD}=0.3)$ (Supplementary Fig. S3), indicating the need of an additional AHL or a regulator present in PsJN wild type to obtain a higher activation of the $\mathrm{P}_{\mathrm{bpI} .1}$ promoter.

\section{P. phytofirmans PsJN QS system regulation in biofilm formation.}

Biofilm formation has been related to effective rhizospheric colonization by PGPB (Meneses et al. 2011; Rinaudi and Giordano 2010). To determine a possible regulation of this trait by QS systems in the PsJN strain, we compared QS mutants with the wild-type strain. Remarkably, biofilm formation was significantly reduced in the $b p I .1$ and $b p I .1-b p I .2$ double mutants grown on $20 \mathrm{mM}$ fructose as carbon source (Fig. 4A). It should be noted that both the bpI.1 single mutant (Zúñiga et al. 2013) and the bpI.1-bpI.2 double mutant (data not shown) presented very low levels of colonization and plant growth promotion. In contrast, no significant differences were observed in $10 \mathrm{mM}$ of fructose in the $b p I .2$ mutant compared with the wild-type strain (Fig. 4A). Biofilm formation was partially recovered in the bpI.1 mutant strain when both $3-\mathrm{OH}$ C8-AHL and 3-oxo-C14-AHL were added to the growth medium (Supplementary Fig. S4). Previous data suggest that biofilm production in $P$. phytofirmans PsJN is influenced by an ECF sigma factor belonging to the ECF26 subfamily, according to Staron et al. (2009) classification, encoded by the ecf26.1 gene (unpublished results). The ecf26.1 mutant

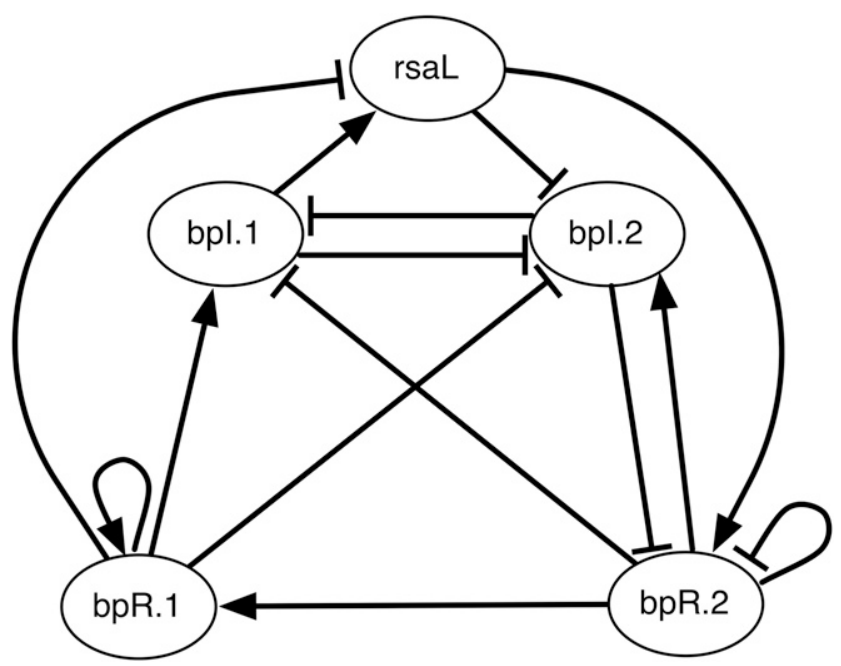

Fig. 2. Model of regulatory network of quorum-sensing systems in Paraburkholderia phytofirmans PsJN. The model shows interactions of each node (bpI.1, bpI.2, bpR.1, bpR.2, and $r s a L)$ with positive or negative regulations. The threshold vector (containing the threshold values for each node) is $0.32,-0.38,-0.86,0.62,-0.79$, respectively. The regulatory network was reconstructed under the threshold Boolean network model using a genetic algorithm, considering the synchronous updating scheme. strain produced significantly less biofilm compared with the wild-type strain (Fig. 4B). In order to explore interactions between the QS system and sigma factor ecf26.1, its transcript levels were determined in the wild-type and QS mutants. We observed differences between ecf 26.1 gene transcript levels, with the $b p I .1$ mutant transcript levels three times lower than the wild-type strain and those of the $b p I .2$ mutant two times higher than the wild-type transcript levels (Fig. 5). It is quite possible that the corresponding transcript levels of the $b p I .1-b p I .2$ double mutant, essentially the same of those of the wild-type strain, resulted from the balance of the contrasting effects in the single mutants (Fig. 5). Transcript levels of the ecf26.1 gene reported here correlated with those of biofilm formation (Fig. 4B) and the decreased total AHL production in the ecf26.1 mutant (data not shown), suggest a possible regulation of the ecf26.1 gene by QS systems.

\section{DISCUSSION}

We reported reduced production of biofilm in the bpI.1 single mutant strain compared with the wild-type strain. We also observed lower transcript levels of gene ecf26.1 sigma factor in the bPI.1 mutant strain compared with the wild-type strain. Additionally, we described, for the first time, a regulatory network that represents QS system interactions when P. phytofirmans PsJN was exposed to $A$. thaliana roots, indicating the importance to the global dynamic in QS gene expression and the genes they regulate. In this network, we observed that expression of both $b p I .1$ and $b p R .1$ genes are induced by $3-\mathrm{OH}-\mathrm{C} 8-\mathrm{AHL}$, but the same AHL seems to repress $r s a L$ gene expression, which is supported by induction data (Fig. 3B). On the other hand, the network indicates that 3-oxo-C14-AHL induces $r s a L, b p R .1$, and bpI.2 gene expression (Fig. 3B) and evidence also supports the direct induction of $b p I .2$ gene promoter by the 3-oxo-C14-AHLbpR. 2 complex (Fig. 3C). Taken together, the presence of an additional regulator to activate the $b p I .1$ gene promoter in the PsJN strain, the analysis of QS gene transcript levels in single and double mutants (Fig. 3A), and the expression pattern of QS genes in the wild type, indicate that QS systems seem to be a complex network that exhibit cross-regulation and an unclear dynamic in the presence of plant roots.

The importance of the bacterial ability to form microcolonies on different parts of the roots is known, from the tip to the elongation zone, hence, they can grow into large populations to form mature biofilms on plant roots (Rudrappa et al. 2007). In a previous study, we observed that the bpI.1 mutant form less biofilm on roots affecting the final colonization of A. thaliana (Zúñiga et al. 2013). Here, we observed less biofilm formation by the bpI.1 mutant compared with the wild-type strain (Fig. 4A). Interestingly, the bpI.2 mutant strain does not present differences in biofilm formation compared with wild-type strain (Fig. 4A). Experiments in Pseudomonas fluorescens showed that biofilm formation in abiotic surfaces has a different structure than a biofilm formed in roots, which would indicate contrasting genetic programs that probably are involved in distinct environmental growth contexts (Barahona et al. 2011). Alternatively, sigma factors are, to some extent, responsible for this differential response, since they coordinate gene expression under different growth conditions or diverse environmental stimuli (Ho and Ellermeier 2012; Tettmann et al. 2014). Some evidence indicates that particular sigma factors are involved in biofilm formation in Pseudomonas strains (Ho and Ellermeier 2012; Masák et al. 2014; Tettmann et al. 2014). Here, we reported that transcript levels of the sigma factor ecf26.1, which is directly involved in biofilm formation, were lower in the bpI.1 mutant strain compared with the PsJN wild-type strain, 
although no differences were observed in transcript levels of bpI.1 gene in the ecf 26.1 gene mutant. In addition, we observed less AHL production in the ecf26.1 mutant strain, as compared with the wild-type strain (data not shown), suggesting that QS control this ECF sigma factor or vice versa. Even more, we observed that the ecf26.1 gene was slightly up-regulated in bpI.2 compared with PsJN wild-type strain (Fig. 4B), which could be related to a tendency of this mutant to produce more biofilm in other carbon sources than plant root exudates. It has been shown that sigma factors and QS systems have crossregulation to control gene expression of each other (Chin-A-Woeng et al. 2000, 2005; Schuster et al. 2003, 2004; Wongtrakoongate et al. 2012). In fact, stationary phase RpoS sigma factor affects the expression of more than $40 \%$ of quorum-controlled genes identified in Pseudomonas aeruginosa (Schuster et al. 2003; 2004). Similar effects of RpoS have been observed in Burkholderia pseudomallei, in which hierarchical control of RpoS over QS-controlled genes was reported (Wongtrakoongate et al. 2012). More experiments are required to determine if lower transcript levels of the ecf26.1 gene observed in the bpI.1 mutant were due to a direct cross-regulation between the sigma factor and the QS system mediated by 3-OH-C8-AHL$b p I . \mathrm{R}$ complex or because another intermediary regulator is operating.

It is known that functions of QS genes, the synthases and regulators, are subjected to various and sometimes different regulation processes (Duan and Surette 2007; Venturi 2006), implicating these genes can be independently regulated, as we observed in results on QS gene expression. Here, we confirmed that both $b p I .2$ effector and $r s a L$ repressor genes from the BraI/RsaL/BraR-like QS system were induced by 3-oxo-C14AHL in P. phytofirmans PsJN (Fig. 3). The conserved QS systems in beneficial Paraburkholderia spp. are related to the LasI/R and PpuI/R AHL QS systems of Pseudomonas aeruginosa and Pseudomonas putida, respectively (SuárezMoreno et al. 2008), in which similar gene-expression control patterns have been observed (Duan and Surette 2007). These QS systems are hierarchical and, in the case of Pseudomonas aeruginosa LasR-3-oxo-C12-AHL, activate the transcription of the $r h I R$ and $r h l I$ genes, which belong to the second QS system of Pseudomonas aeruginosa. Also, it is known that the RsaL repressor controls the expression of over 200 genes in Pseudomonas aeruginosa, half of which are also QS-controlled (Rampioni et al. 2009). It is possible that the RsaL repressor in $P$. phytofirmans PsJN has a similar function; mutant strains and transcriptional studies are required to confirm its role in this strain. In the present study, we report that the BpI.1/BpR.1 QS system responds to $3-\mathrm{OH}-\mathrm{C} 8$-AHL, increasing transcript levels of the $b p I .1$ and $b p R .1$ genes, but an additional regulator for the 3-OH-C8-AHL-BpR.1 complex is necessary to a higher

Fig. 3. Transcriptional levels of quorum-sensing (QS) system genes in Paraburkholderia phytofirmans PsJN. A, Relative transcript levels of QS regulatory genes $b p R .1, b p R .2$, and $r s a L$ in $P$. phytofirmans PsJN wild-type strain and in the $b p I .1, b p I .2$, and $b p I .1-b p I .2$ single and double mutants at stationary phase of growth (optical density at $600 \mathrm{~nm}\left[\mathrm{OD}_{600}\right]=1.8$ ). B, Relative transcript levels of QS system genes in $P$. phytofirmans PsJN wild-type strain induced with $2 \mu \mathrm{M} 3-\mathrm{OH}-\mathrm{C} 8$-AHL (acyl-homoserine lactones) and 3-oxo-C14-AHL, at exponential growth phase $\mathrm{OD}_{600}=0.7$. Ethyl acetate (EA) solvent was used as a control in noninduced tests. Data are means \pm standard errors of three biological replicates. Different letters are used to indicate means that differ significantly (one-way analysis of variance Tukey's honestly significant difference tests, $P<0.05)$. C, $b p I .1$, bpI.2, and $r s a L$ gene promoter activities in Escherichia coli, in the presence of $2 \mu \mathrm{M} 3-\mathrm{OH}-\mathrm{C} 8-\mathrm{AHL}$ or 3-oxo-C14-AHL. EA was used as negative control of induction. Data are means \pm standard errors of three biological replicates. activation of $b p I .1$ promoter (Fig. 3). It is possible that a specific sigma factor could be required to better $b p I .1$ promoter activation in the PsJN strain, and we propose that ecf26.1 sigma factor could be a good candidate. We also showed that transcript levels of the rsaL gene were down-regulated in the presence of 3-OH-C8-AHL (Fig. 1B), suggesting a crossregulation between BpI.1/BpR.1 and Bp.I.2/rsaL/BpR.2 QS systems in $P$. phytofirmans PsJN strain. No changes were observed in the $b p R .2$ gene transcript levels in the presence of

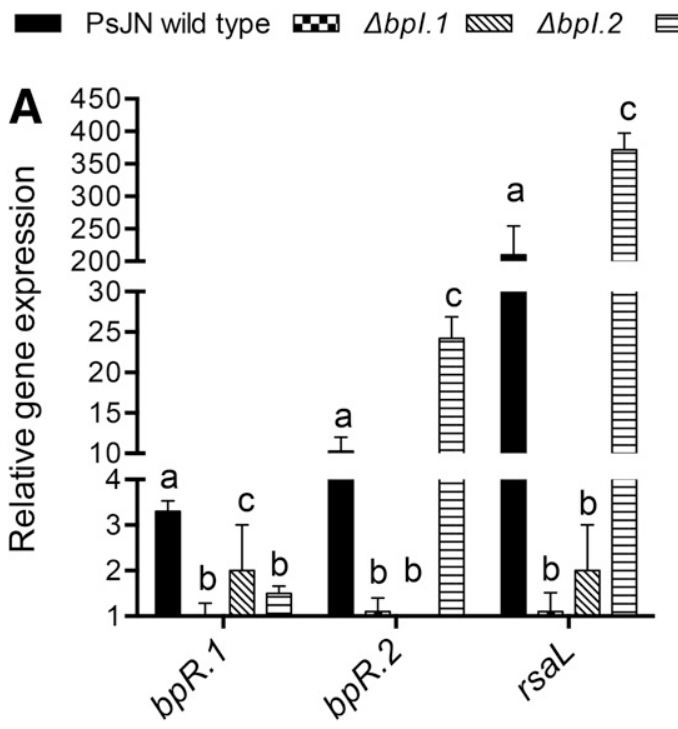

$\mathbf{B}$ 3OH-C8-AHL $\Longrightarrow 30 \times 0-C 14-\mathrm{AHL} \quad \mathbf{D E} \mathrm{EA}$
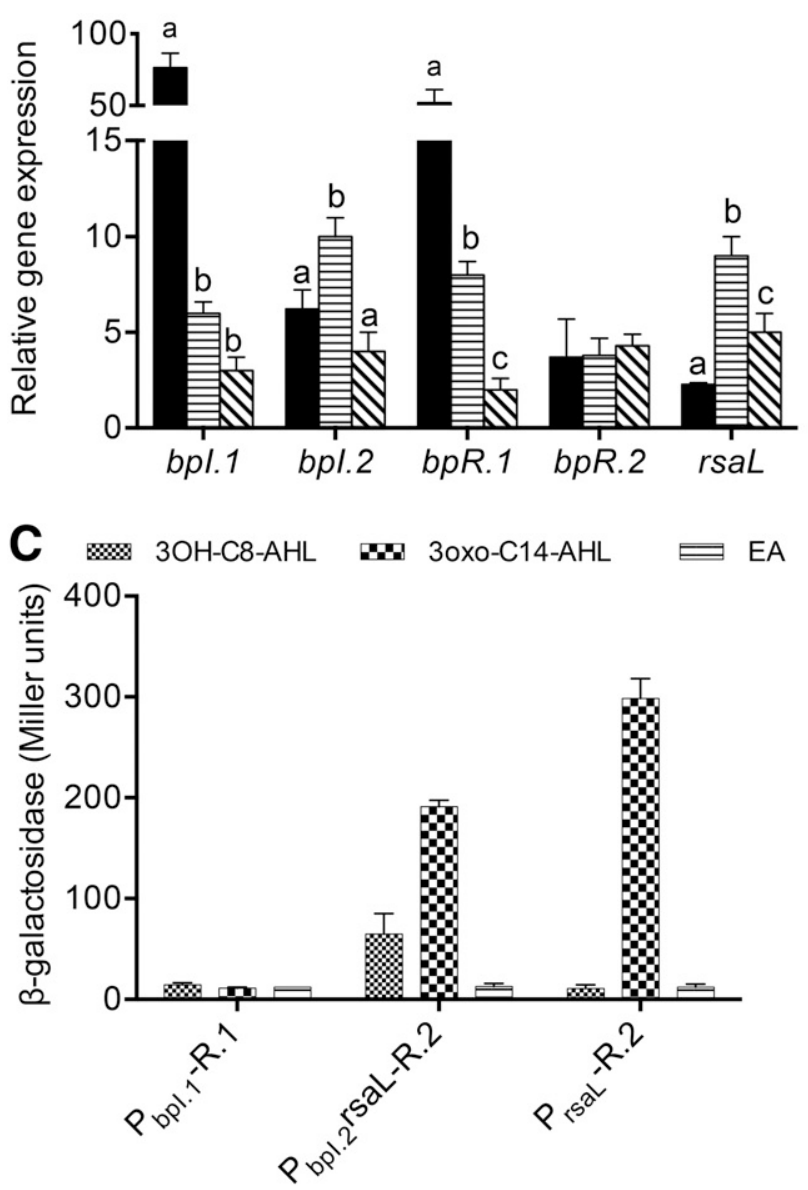
3-oxo-C14-AHL. There are several bacterial species that harbor in their genome multiple AHL-based QS systems that can be interconnected in an independent, synergistic or repressed regulatory network (Cha et al. 1998; Atkinson et al. 2008). Examples of this are found in the above-mentioned Pseudomonas aeruginosa (Lee and Zhang 2015; Schuster and Greenberg 2006; Schuster et al. 2003), in which the LasR regulator can form a multimer and bind las-box sequences only in the presence of 3-oxo-C12-AHL (Kiratisin et al. 2002) and RhIR dimerizes and binds DNA both in the presence and absence of C4-AHL (Medina et al. 2003; Ventre et al. 2003; Venturi 2006), creating a complex QS regulatory network, as we have observed in P. phytofirmans PsJN.

Using the temporal expression profile of QS systems of $P$. phytofirmans PsJN in the presence of plant roots, we were enabled to observe the changes in QS genes in response to the plant. The differences found in transcript levels corresponding to each QS system gene in planted and unplanted conditions
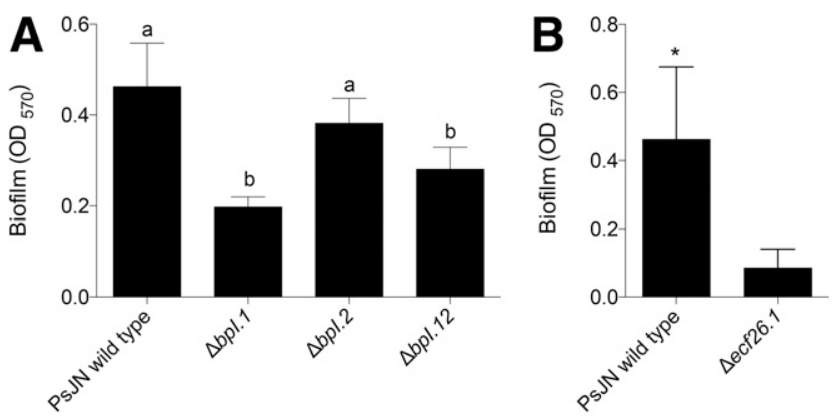

Fig. 4. Analysis of biofilm formation. A, Biofilm formation of Paraburkholderia phytofirmans PsJN wild-type strain and the $b p I .1, b p I .2$, and bpI.1-bpI.2 single and double mutant strains on $20 \mathrm{mM}$ fructose. B, Biofilm formation of $P$. phytofirmans PsJN wild-type strain and the ecf26.1 mutant strain on $20 \mathrm{mM}$ fructose. Biofilm formation was measured after $48 \mathrm{~h}$ of incubation. Bars are means \pm standard errors of three biological replicates. Different letters are used to indicate means that differ significantly (oneway analysis of variance Tukey's honestly significant difference tests, $P<0.05)$.

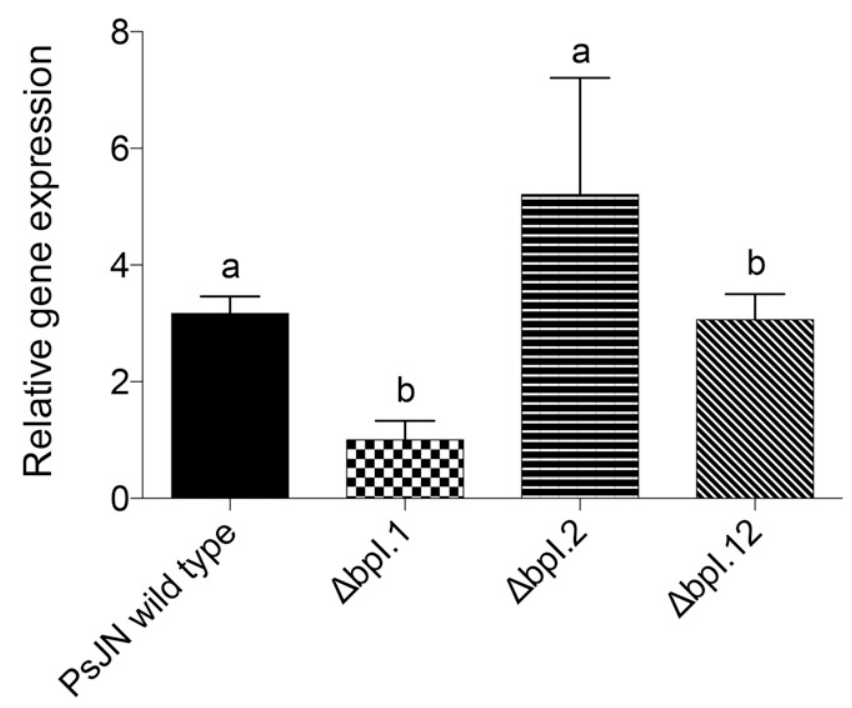

Fig. 5. Relative transcript levels of the ecf26.1 gene in Paraburkholderia phytofirmans PsJN wild-type strain and the bpI.1, bpI.2 and bpI.1-bpI.2 single and double mutants at stationary phase of growth (optical density at $600 \mathrm{~nm}\left[\mathrm{OD}_{600}\right]=1.8$ ). Data are means \pm standard errors of three biological replicates. Different letters are used to indicate means that differ significantly (one-way analysis of variance Tukey's honestly significant difference tests, $P<0.05)$. indicate that autoinducer and response-regulator genes could be independently regulated, influenced by environmental context and playing different roles under diverse conditions. Similar results were observed in temporal expression profiles of Pseudomonas aeruginosa QS genes, in which the hierarchic structure of the networks is regulated in response to changes in the environment (Duan and Surette 2007).

It is known that cell-to-cell communication in bacteria implies a complex regulatory network that is very attractive to disciplines such as engineering, because mathematical equations can provide models of networks that allow the understanding of cell-to-cell communication at a systemic level (Dallidis and Karafyllidis 2014; Goryachev 2011). Here, we used a Boolean network to represent a regulatory model of QS systems. Even though this tool presents some limitations, it enabled us to integrate all the information about QS systems regulation and get a successful model of QS network. This network was obtained using transcript levels of QS system genes expressed on inoculated PsJN bacteria in plant roots, which gave us information about the regulon formed by genes involved. Moreover, this modeling approach could be a useful tool to apply in other Burkholderiales species that share similar QS systems, to take all the information about each species and produce global models of QS networks in this genus in different environmental contexts.

\section{MATERIALS AND METHODS}

\section{Bacterial strains and plasmids.}

P. phytofirmans PsJN was obtained from A. Sessitsch. Wild-type PsJN and the three mutant strains (bpI.1, bpI.2, bpI.1-bpI.2) were grown on Dorn mineral salts medium (Dorn et al. 1974) containing $10 \mathrm{mM}$ fructose as the sole carbon and energy source and, if required, kanamycin $\left(50 \mu \mathrm{g} \mathrm{ml}^{-1}\right)$, spectinomycin $\left(100 \mu \mathrm{g} \mathrm{ml}^{-1}\right)$, or gentamicin $\left(30 \mu \mathrm{g} \mathrm{ml}^{-1}\right)$, at $30^{\circ} \mathrm{C}$ for $12 \mathrm{~h}$.

\section{Construction of $P$. phytofirmans PsJN mutants.}

Mutant strains $b p I .1$ and $b p I .2$ were constructed as described by Zúñiga et al. (2013). To obtain the bpI.1- bpI.2 double mutant, we introduced a second plasmid in the bpI.2 mutant, constructed using the $b p I .1$ PCR product (employing bpI.1mut primer pairs, listed in Supplementary Table S1), to assembly it in a pGEM-Tgen ${ }^{+}$vector modified with a gentamicin antibiotic resistance. This plasmid was electroporated in the P. phytofirmans PsJN bpI.2 mutant to get one recombination event disruption of the target gene, and recombinants were selected on Luria-Bertani (LB) agar, containing spectinomycin $(100 \mu \mathrm{g} / \mathrm{ml})$ and gentamicin $(30 \mu \mathrm{g} / \mathrm{ml})$, to obtain the PsJN bpI.1-bpI.2 double mutant. Correct insertions in mutant strains were confirmed by PCR and sequencing.

RNA extraction, cDNA synthesis, and qRT-PCR analyses.

Cells of $P$. phytofirmans PsJN wild type and $b p I .1, b p I .2$, and $b p I .1-b p I .2$ single and double mutant strains were grown overnight in minimal medium with $10 \mathrm{mM}$ fructose, to inoculate a fresh culture medium. For the stationary growth phase expression analysis, we grew the cells until optical density at $600 \mathrm{~nm}\left(\mathrm{OD}_{600}\right)=1.8$. To carry out expression analysis in wildtype PsJN induced with AHLs, we grew cells until $\mathrm{OD}_{600}=0.7$ (exponential phase of growth), and then, we supplemented this culture with $2 \mu \mathrm{M} 3-\mathrm{OH}-\mathrm{C} 8-\mathrm{AHL}$ or 3-oxo-C14-AHL or with solvent ethyl acetate as a control and, finally, incubated cultures for $1 \mathrm{~h}$. To evaluate gene expression in the presence of plants, we inoculated roots of $A$. thaliana plants, with 14 days of growth on hydroponic system, with $1 \times 10^{4}$ cells of PsJN wildtype strain for $48 \mathrm{~h}$, and then, we took culture samples after 0,5 , 
and $30 \mathrm{~min}, 1,2,24$, and $48 \mathrm{~h}$. The same hydroponic growth system, was used to inoculate bacteria but without plants, as a control treatment.

To extract RNA, we took $4 \mathrm{ml}$ of each culture, using RNA Protect bacteria reagent and RNeasy mini kit (Qiagen, Chatsworth, CA, U.S.A.). The RNA was quantified using a GeneQuant 1300 Spectrophotometer (GE Healthcare, Piscataway, NJ, U.S. A.) and was treated with TURBO DNase kit (Ambion, Austin, TX, U.S.A.) to remove DNA contamination. The cDNA synthesis was performed, using ImProm-II reverse transcription system (Promega Corp., Madison, WI, U.S.A.), with $1 \mu \mathrm{g}$ of RNA in $20 \mu$ l of reaction.

RT-PCR was performed using the Brilliant SYBR green qPCR master reagent kit (Agilent Technologies, Santa Clara, CA, U.S.A.) and the Eco real-time PCR detection system (Illumina, San Diego, CA, U.S.A.). The PCR mixture $(15 \mu \mathrm{l})$ contained $2.0 \mu$ l of template cDNA (diluted 1:10) and $140 \mathrm{nM}$ each primer. Amplification was performed under the following conditions: $95^{\circ} \mathrm{C}$ for $10 \mathrm{~min}$; followed by 40 cycles of $94^{\circ} \mathrm{C}$ for $30 \mathrm{~s}, 60^{\circ} \mathrm{C}$ for $30 \mathrm{~s}$, and $72^{\circ} \mathrm{C}$ for $30 \mathrm{~s}$; followed by a melting cycle from 55 to $95^{\circ} \mathrm{C}$. Relative gene expression calculations were conducted as described in the software manufacturer's instructions. An accurate ratio between the expression of the gene of interest (GOI) and the housekeeping (HK) gene was calculated according to the expression $2-(\Delta \mathrm{CtGOI}-\mathrm{HK})$. Then, gene expression levels were normalized to the average value of the expressions in the control treatment. 16S rRNA (Bphyt_R0071) was used as a HK gene. qRT-PCR analysis primer pairs for efc26.1 (Bphyt_1666), bpI.1 (Bphyt_0126), bpI.2 (Bphyt_4275), bpR.1 (Bphyt_0127), bpR.2 (Bphyt_4277), and rsaL (Bphyt_4276) genes were used.

\section{Construction of $l a c Z$ reporter fusions.}

Putative promoter regions were fused to the $l a c Z$ gene from pKGWP0 (Marín et al. 2010). PCR products comprising approximately $200 \mathrm{bp}$ of the upstream region contiguous to translational starts of the $b p I .1, b p I .2$, and $r s a L$ genes were obtained. The amplified DNA fragments were then cloned into the XhoI-KpnI restriction site of pKGWP0, forming $\mathrm{P}_{\mathrm{bpI} .1-1 \mathrm{lacZ}}$, $\mathrm{P}_{\mathrm{bpI} .2}$ rsaL-lacZ, and $\mathrm{P}_{\mathrm{rsaL}}$-lacZ plasmids, were transferred into $E$. coli, and were selected in LB medium supplemented with $100 \mu \mathrm{g}$ of spectinomycin per milliliter. $b p R .1$ and $b p R .2$ gene sequences were amplified using bpR.1.g and bpR.2.g primer pairs. Primers were designed containing an additional $20 \mathrm{bp}$ at the terminal sequence that overlap with the downstream $\mathrm{P}_{\mathrm{BAD}}$ promoter from the pBS1 vector (Bronstein et al. 2005), which were joined into a covalently sealed molecule in a one-step isothermal reaction, as described by Gibson et al. (2009). The recombinant plasmid PBS1-BpR.1 was electroporated in E. coli $\mathrm{P}_{\text {bpI.1 }}$-lacZ and PBS1-BpR.2 was electroporated in E. coli $\mathrm{P}_{\text {bpI.2 }}$ rsaL-lacZ and $\mathrm{P}_{\mathrm{rsaL}}$-lacZ. E. coli strains were selected in LB medium supplemented with spectinomycin $\left(100 \mu \mathrm{g} \mathrm{ml}^{-1}\right)$ and gentamycin $\left(30 \mu \mathrm{g} \mathrm{ml} \mathrm{m}^{-1}\right)$. $\beta$-Galactosidase assays were performed according to standard protocols (Miller 1972) after $4 \mathrm{~h}$ of incubation, using 3OH-C8-AHL and 3OXO-C14-AHL $(2 \mu \mathrm{M})$ as inducer.

\section{Biofilm formation.}

Biofilm formation was evaluated using the microtiter plate biofilm assay as described by Merritt et al. (2005). We grew bpI.1, bpI.2, and $b p I .1-b p I .2$ mutants and PsJN wild-type strain in $2 \mathrm{ml}$ of Dorn mineral salts medium (Dorn et al. 1974) containing $10 \mathrm{mM}$ fructose until stationary phase. Then, 1:100 diluted cultures in Dorn mineral medium were used to inoculate microtiter plate wells filled with Dorn mineral medium containing $20 \mathrm{mM}$ fructose. After $48 \mathrm{~h}$ of incubation at $30^{\circ} \mathrm{C}$, planktonic bacteria were removed and each well was washed with distilled water. Biofilm mass was measured using $0.1 \%$ crystal violet ethanolic solution. The $\mathrm{OD}_{570}$ was determined by spectrophotometry.

\section{Growth of A. thaliana.}

A. thaliana ecotype Col-0 was used. Seeds were surface sterilized with $50 \%$ ( $\mathrm{vol} / \mathrm{vol})$ commercial chlorine bleach for $7 \mathrm{~min}$ and were washed three times in sterile distilled water. Then, seeds were kept at $4^{\circ} \mathrm{C}$ for 2 days in the absence of light to produce stratification. After that, 200 seeds were sown in sterile Magenta culture vessels, adapted for sterile hydroponic growth using $250 \mu \mathrm{m}$ polypropylene mesh as substrate for plant growth and a support stand constructed from two notched rectangles of polycarbonate. The plant growth chamber was run with a cycle of $16 \mathrm{~h}$ of light and $8 \mathrm{~h}$ of darkness and a temperature of $22 \pm 2{ }^{\circ} \mathrm{C}$. After 14 days, plants were inoculated. Three biological replicates were carried out for each treatment.

\section{Boolean network modeling.}

Let $\boldsymbol{x}$ be a finite set of $n$ variables (genes), $\boldsymbol{x}=\left\{\mathrm{x}_{1}, \ldots, x_{n}\right\}$, with $x_{i} \in\{0,1\}$ for $i=1, \ldots, n$. A Boolean network is a pair $(G$, $F)$, where $G=(\mathrm{V}, \mathrm{E})$ is a finite directed graph with $\mathrm{V}$ being the set of $n$ nodes and $\mathrm{E}$ the set of edges. $F$ is a Boolean function, $F:\{0,1\}^{n} \rightarrow\{0,1\}^{n}$ composed of $n$ local functions $f_{i}:\{0,1\}^{n} \rightarrow$ $\{0,1\}$. In this work, we used the synchronous or parallel updating scheme, i.e., at each time step, all the nodes are updated at the same time. The dynamics of the network (how the values of the nodes change through time) eventually converges to attractors (steady states), which can be either a fixed point where, once the network reaches that state, it can never leave it or a limit cycle, where the network returns to a previous state with a certain periodicity. The set of states that can lead the network to a specific attractor is called the basin of attraction. For the reconstruction of Boolean networks from data, it has become more common to see the threshold Boolean network version, which considers weights for the edges and threshold values for each node, then, the update is carried using a Boolean Heaviside function that depends linearly on its inputs (Goles et al. 2013). More formally, in a threshold Boolean network, updates of each node are computed by

$$
\begin{gathered}
x_{i}(t+1)=H\left(\sum_{j=1}^{n} w_{i j} x_{j}(t)-\theta_{i}\right) \\
H(z)= \begin{cases}1, & \text { if } z \geq 0 \\
0, & \text { if } z<0\end{cases}
\end{gathered}
$$

with $w_{i j}$ the weight of the edge coming from node $j$ into node $i$, and $\theta_{i}$ the activation threshold of node $i$. The weights and thresholds are the network's parameters.

\section{Regulatory network reconstruction using a threshold Boolean network.}

The expression levels of QS system genes were obtained through time from cells collected at the exponential phase of growing $\left(\mathrm{OD}_{600}=0.7\right)$. RNA samples were then taken after 5 , $15,30,60$, and $120 \mathrm{~min}, 24$, and $48 \mathrm{~h}$. The transcript levels of $b p I .1, b p I .2, b p R .1, b p R .2$, and $r s a L$ genes were binarized using the $\mathrm{k}$-means clustering algorithm with $\mathrm{k}=2$. Using these binary data, we inferred a threshold Boolean network, using an evolutionary computation approach (Ruz et al. 2015). In particular, a genetic algorithm was used to find the network's parameters. In the case of the weights, we restricted the search for values within the set $\{-1,0,1\}$, whereas, for the threshold values, we consider continuous values within the range $[0,1]$. 


\section{Statistical analysis.}

Data for biofilm formation and gene transcript levels were statistically analyzed, using one-way analysis of variance, to compare multiple means. When analysis of variance showed significant treatment effects, the Tukey's honestly significant difference $(P<$ 0.05 ) test was applied to make comparisons between treatments.

\section{ACKNOWLEDGMENTS}

This work was funded by the Fondo Nacional de Desarrollo Científico y Tecnológico (FONDECYT) grant 1151130, the Comisión Nacional de Investigación Científica y Tecnológica (CONICYT) grant FB 0002-2014, the Millennium Nuclei in "Plant Functional Genomics" grant P/10-062-F and in "Plant Systems and Synthetic Biology" grant NC130030. Additional support from postdoctoral FONDECYT grants 3140031 (to A. Zúñiga), and 3140033 (to R. Donoso) is also acknowledged.

\section{LITERATURE CITED}

Aguilar, C., Bertani, I., and Venturi, V. 2003. Quorum-sensing system and stationary-phase sigma factor ( $r p o S$ ) of the onion pathogen Burkholderia cepacia genomovar I type strain, ATCC 25416. Appl. Environ. Microbiol. 69:1739-1747.

Atkinson, S., Chang, C. Y., Patrick, H. L., Buckley, C. M., Wang, Y., Sockett, R. E., Cámara, M., and Williams, P. 2008. Functional interplay between the Yersinia pseudotuberculosis YpsRI and YtbRI quorum sensing systems modulates swimming motility by controlling expression of flhDC and fliA. Mol. Microbiol. 69:137-151.

Audretsch, C., Lopez, D., Srivastava, M., Wolz, C., and Dandekar, T. 2013. A semi-quantitative model of quorum-sensing in Staphylococcus aureus, approved by microarray meta-analyses and tested by mutation studies. Mol. Biosyst. 9:2665-2680.

Bakker, P. A., Berendsen, R. L., Doornbos, R. F., Wintermans, P. C., and Pieterse, C. M. 2013. The rhizosphere revisited: Root microbiomics. Front. Plant Sci. 4:165.

Barahona, E., Navazo, A., Martínez-Granero, F., Zea-Bonilla, T., PérezJiménez, R. M., Martín, M., and Rivilla, R. 2011. Pseudomonas fluorescens F113 mutant with enhanced competitive colonization ability and improved biocontrol activity against fungal root pathogens. Appl. Environ. Microbiol. 77:5412-5419.

Bauer, W. D., and Mathesius, U. 2004. Plant responses to bacterial quorum sensing signals. Curr. Opin. Plant Biol. 7:429-433.

Bertini, E. V., Nieto-Peñalver, C. G., Leguina, A. C., Irazusta, V. P., and de Figueroa, L. I. 2014. Gluconacetobacter diazotrophicus PAL5 possesses an active quorum sensing regulatory system. Anton. Leeuw. Int. J. G. 106:497-506.

Bhattacharyya, P. N., and Jha, D. K. 2012. Plant growth-promoting rhizobacteria (PGPR): Emergence in agriculture. World J. Microbiol. Biotechnol. 28:1327-1350.

Bronstein, P. A., Marrichi, M., Cartinhour, S., Schneider, D. J., and DeLisa, M. P. 2005. Identification of a twin-arginine translocation system in Pseudomonas syringae pv. tomato DC3000 and its contribution to pathogenicity and fitness. J. Bacteriol. 187:8450-8461.

Chapalain, A., Vial, L., Laprade, N., Dekimpe, V., Perreault, J., and Déziel, E. 2013. Identification of quorum sensing-controlled genes in Burkholderia ambifaria. MicrobiologyOpen 2:226-242.

Chin-A-Woeng, T. F., Bloemberg, G. V., Mulders, I. H., Dekkers, L. C., and Lugtenberg, B. J. 2000. Root colonization by phenazine-1-carboxamideproducing bacterium Pseudomonas chlororaphis PCL1391 is essential for biocontrol of tomato foot and root rot. Mol. Plant-Microbe Interact. 13:1340-1345.

Chin-A-Woeng, T. F., van den Broek, D., Lugtenberg, B. J., and Bloemberg, G. V. 2005. The Pseudomonas chlororaphis PCL1391 sigma regulator psrA represses the production of the antifungal metabolite phenazine-1carboxamide. Mol. Plant-Microbe Interact. 18:244-253.

Choudhary, K. S., Hudaiberdiev, S., Gelencsér, Z., Gonçalves Coutinho, B., Venturi, V., and Pongor, S. 2013. The organization of the quorum sensing luxI/R family genes in Burkholderia. Int. J. Mol. Sci. 14:13727-13747.

Coenye, T., and Vandamme, P. 2003. Diversity and significance of Burkholderia species occupying diverse ecological niches. Environ. Microbiol. 5:719-729.

Compant, S., Kaplan, H., Sessitsch, A., Nowak, J., Ait Barka, E., and Clément, C. 2008. Endophytic colonization of Vitis vinifera L. by Burkholderia phytofirmans strain PsJN: From the rhizosphere to inflorescence tissues. FEMS Microbiol. Ecol. 63:84-93.

Coutinho, B. G., Mitter, B., Talbi, C., Sessitsch, A., Bedmar, E. J., Halliday, N., James, E. K., Cámara, M., and Venturi, V. 2013. Regulon studies and in planta role of the BraI/R quorum-sensing system in the plant-beneficial Burkholderia cluster. Appl. Environ. Microbiol. 79:4421-4432.

Dallidis, S. E., and Karafyllidis, I. G. 2014. Boolean network model of the Pseudomonas aeruginosa quorum sensing circuits. IEEE Trans. Nanobioscience 13:343-349.

Darch, S. E., West, S. A., Winzer, K., and Diggle, S. P. 2012. Densitydependent fitness benefits in quorum-sensing bacterial populations. Proc. Natl. Acad. Sci. U.S.A. 109:8259-8263.

Dekkers, L. C., Bloemendaal, C. J., de Weger, L. A., Wijffelman, C. A., Spaink, H. P., and Lugtenberg, B. J. 1998. A two-component system plays an important role in the root-colonizing ability of Pseudomonas fluorescens strain WCS365. Mol. Plant-Microbe Interact. 11:45-56.

Depoorter, E., Bull, M. J., Peeters, C., Coenye, T., Vandamme, P., and Mahenthiralingam, E. 2016. Burkholderia: An update on taxonomy and biotechnological potential as antibiotic producers. Appl. Microbiol. Biotechnol. 100:5215-5229.

Diggle, S. P., Griffin, A. S., Campbell, G. S., and West, S. A. 2007. Cooperation and conflict in quorum-sensing bacterial populations. Nature 450:411-414.

Dorn, E., Hellwig, M., Reineke, W., and Knackmuss, H. J. 1974. Isolation and characterization of a 3-chlorobenzoate degrading pseudomonad. Arch. Microbiol. 99:61-70.

Duan, K., and Surette, M. G. 2007. Environmental regulation of Pseudomonas aeruginosa PAO1 Las and Rhl quorum-sensing systems. J. Bacteriol. 189:4827-4836.

Fernandez, O., Theocharis, A., Bordiec, S., Feil, R., Jacquens, L., Clément, C., Fontaine, F., and Barka, E. A. 2012. Burkholderia phytofirmans PsJN acclimates grapevine to cold by modulating carbohydrate metabolism. Mol. Plant-Microbe Interact. 25:496-504.

Fuqua, C., and Greenberg, E. P. 2002. Listening in on bacteria: Acylhomoserine lactone signalling. Nat. Rev. Mol. Cell Biol. 3:685-695.

Gamage, A. M., Shui, G., Wenk, M. R., and Chua, K. L. 2011. $\mathrm{N}$-Octanoylhomoserine lactone signalling mediated by the BpsI-BpsR quorum sensing system plays a major role in biofilm formation of Burkholderia pseudomallei. Microbiology 157:1176-1186.

Gibson, D. G., Young, L., Chuang, R. Y., Venter, J. C., Hutchison, C. A., 3rd, and Smith, H. O. 2009. Enzymatic assembly of DNA molecules up to several hundred kilobases. Nat. Methods 6:343-345.

Goles, E., Montalva, M., and Ruz, G. A. 2013. Deconstruction and dynamical robustness of regulatory networks: Application to the yeast cell cycle networks. Bull. Math. Biol. 75:939-966.

Goo, E., An, J. H., Kang, Y., and Hwang, I. 2015. Control of bacterial metabolism by quorum sensing. Trends Microbiol. 23:567-576.

Goryachev, A. B. 2011. Understanding bacterial cell-cell communication with computational modeling. Chem. Rev. 111:238-250.

Götz, C., Fekete, A., Gebefuegi, I., Forczek, S. T., Fuksová, K., Li, X., Englmann, M., Gryndler, M., Hartmann, A., Matucha, M., Schmitt-Kopplin, P., and Schröder, P. 2007. Uptake, degradation and chiral discrimination of $N$-acylD/L-homoserine lactones by barley (Hordeum vulgare) and yam bean (Pachyrhizus erosus) plants. Anal. Bioanal. Chem. 389:1447-1457.

Hernández-Reyes, C., Schenk, S. T., Neumann, C., Kogel, K. H., and Schikora, A. 2014. $\mathrm{N}$-acyl-homoserine lactones-producing bacteria protect plants against plant and human pathogens. Microb. Biotechnol. 7:580-588.

Ho, T. D., and Ellermeier, C. D. 2012. Extra cytoplasmic function $\sigma$ factor activation. Curr. Opin. Microbiol. 15:182-188.

Idris, E. E., Iglesias, D. J., Talon, M., and Borriss, R. 2007. Tryptophandependent production of indole-3-acetic acid (IAA) affects level of plant growth promotion by Bacillus amyloliquefaciens FZB42. Mol. PlantMicrobe Interact. 20:619-626.

Kiratisin, P., Tucker, K. D., and Passador, L. 2002. LasR, a transcriptional activator of Pseudomonas aeruginosa virulence genes, functions as a multimer. J. Bacteriol. 184:4912-4919.

Kraiser, T., Gras, D. E., Gutiérrez, A. G., González, B., and Gutiérrez, R. A. 2011. A holistic view of nitrogen acquisition in plants. J. Exp. Bot. 62:1455-1466.

Lee, J., and Zhang, L. 2015. The hierarchy quorum sensing network in Pseudomonas aeruginosa. Protein Cell 6:26-41.

Lery, L. M., Hemerly, A. S., Nogueira, E. M., von Krüger, W. M., and Bisch, P. M. 2011. Quantitative proteomic analysis of the interaction between the endophytic plant-growth-promoting bacterium Gluconacetobacter diazotrophicus and sugarcane. Mol. Plant-Microbe Interact. 24:562-576.

López-Bucio, J., Campos-Cuevas, J. C., Hernández-Calderón, E., VelásquezBecerra, C., Farías-Rodríguez, R., Macías-Rodríguez, L. I., and Valencia-Cantero, E. 2007. Bacillus megaterium rhizobacteria promote growth and alter root-system architecture through an auxin- and ethylene-independent signaling mechanism in Arabidopsis thaliana. Mol. Plant-Microbe Interact. 20:207-217.

Lugtenberg, B., and Kamilova, F. 2009. Plant-growth-promoting rhizobacteria. Annu. Rev. Microbiol. 63:541-556. 
Malott, R. J., Baldwin, A., Mahenthiralingam, E., and Sokol, P. A. 2005. Characterization of the cciIR quorum-sensing system in Burkholderia cenocepacia. Infect. Immun. 73:4982-4992.

Marín, M., Pérez-Pantoja, D., Donoso, R., Wray, V., González, B., and Pieper, D. H. 2010. Modified 3-oxoadipate pathway for the biodegradation of methylaromatics in Pseudomonas reinekei MT1. J. Bacteriol. 192:1543-1552.

Masák, J., Čejková, A., Schreiberová, O., and Rezanka, T. 2014. Pseudomonas biofilms: Possibilities of their control. FEMS Microbiol. Ecol. 89:1-14.

McAnulla, C., Edwards, A., Sánchez-Contreras, M., Sawers, R. G., and Downie, J. A. 2007. Quorum-sensing-regulated transcriptional initiation of plasmid transfer and replication genes in Rhizobium leguminosarum biovar viciae. Microbiology 153:2074-2082.

Medina, G., Juárez, K., Díaz, R., and Soberón-Chávez, G. 2003. Transcriptional regulation of Pseudomonas aeruginosa rhlR, encoding a quorum-sensing regulatory protein. Microbiology 149:3073-3081.

Meneses, C. H., Rouws, L. F., Simoes-Araujo, J. L., Vidal, M. S., and Baldani, J. I. 2011. Exopolysaccharide production is required for biofilm formation and plant colonization by the nitrogen-fixing endophyte Gluconacetobacter diazotrophicus. Mol. Plant-Microbe Interact. 24:1448-1458.

Merritt, J. H., Kadouri, D. E., and O'Toole, G. A. 2005. Growing and analyzing static biofilms. Curr. Protoc. Microbiol. 1:1-18.

Miller, J. H. 1972. Experiments in Molecular Genetics. Cold Spring Harbor Laboratory Press, Cold Spring Harbor, NY, U.S.A

Ortíz-Castro, R., Contreras-Cornejo, H. A., Macías-Rodríguez, L., and López-Bucio, J. 2009. The role of microbial signals in plant growth and development. Plant Signal. Behav. 4:701-712.

Ortíz-Castro, R., Martínez-Trujillo, M., and López-Bucio, J. 2008. N-acylL-homoserine lactones: A class of bacterial quorum-sensing signals alter post-embryonic root development in Arabidopsis thaliana. Plant Cell Environ. 31:1497-1509.

Packiavathy, I. A., Sasikumar, P., Pandian, S. K., and Veera Ravi, A. 2013. Prevention of quorum-sensing-mediated biofilm development and virulence factors production in Vibrio spp. by curcumin. Appl. Microbiol. Biotechnol. 97:10177-10187.

Pérez-Montaño, F., Jiménez-Guerrero, I., Contreras Sánchez-Matamoros, R., López-Baena, F. J., Ollero, F. J., Rodríguez-Carvajal, M. A., Bellogín, R. A., and Espuny, M. R. 2013. Rice and bean AHL-mimic quorum-sensing signals specifically interfere with the capacity to form biofilms by plant-associated bacteria. Res. Microbiol. 164:749-760.

Pérez-Pantoja, D., Donoso, R., Agulló, L., Córdova, M., Seeger, M., Pieper, D. H., and González, B. 2012. Genomic analysis of the potential for aromatic compounds biodegradation in Burkholderiales. Environ. Microbiol. 14:1091-1117.

Quiñones, B., Dulla, G., and Lindow, S. E. 2005. Quorum sensing regulates exopolysaccharide production, motility, and virulence in Pseudomonas syringae. Mol. Plant-Microbe Interact. 18:682-693.

Rampioni, G., Schuster, M., Greenberg, E. P., Zennaro, E., and Leoni, L. 2009. Contribution of the RsaL global regulator to Pseudomonas aeruginosa virulence and biofilm formation. FEMS Microbiol. Lett. 301:210-217.

Rinaudi, L. V., and Giordano, W. 2010. An integrated view of biofilm formation in rhizobia. FEMS Microbiol. Lett. 304:1-11.

Rudrappa, T., Quinn, W. J., Stanley-Wall, N. R., and Bais, H. P. 2007. A degradation product of the salicylic acid pathway triggers oxidative stress resulting in down-regulation of Bacillus subtilis biofilm formation on Arabidopsis thaliana roots. Planta 226:283-297.

Ruz, G. A., Timmermann, T., and Goles, E. 2015. Reconstruction of a GRN model of salt stress response in Arabidopsis using genetic algorithms. Pages 1-8 in: The 2015 IEEE Conference on Computational Intelligence in Bioinformatics and Computational Biology (CIBCB 2015), Niagara Falls, Canada, August 12-15, 2015. IEEE, New York.

Ryu, C. M., Choi, H. K., Lee, C. H., Murphy, J. F., Lee, J. K., and Kloepper, J. W. 2013. Modulation of quorum sensing in acylhomoserine lactoneproducing or -degrading tobacco plants leads to alteration of induced systemic resistance elicited by the rhizobacterium Serratia marcescens. Plant Pathol. J. 29:182-192.

Sánchez-Contreras, M., Bauer, W. D., Gao, M., Robinson, J. B., and Allan Downie, J. 2007. Quorum-sensing regulation in rhizobia and its role in symbiotic interactions with legumes. Philos. Trans. R. Soc. Lond. B Biol. Sci. 362:1149-1163.

Sawana, A., Adeolu, M., and Gupta, R. S. 2014. Molecular signatures and phylogenomic analysis of the genus Burkholderia: Proposal for division of this genus into the emended genus Burkholderia containing pathogenic organisms and a new genus Paraburkholderia gen. nov. harboring environmental species. Front. Genet. 5:429.

Schuster, M., and Greenberg, E. P. 2006. A network of networks: Quorumsensing gene regulation in Pseudomonas aeruginosa. Int. J. Med. Microbiol. 296:73-81.
Schuster, M., Hawkins, A. C., Harwood, C. S., and Greenberg, E. P. 2004 The Pseudomonas aeruginosa RpoS regulon and its relationship to quorum sensing. Mol. Microbiol. 51:973-985.

Schuster, M., Lostroh, C. P., Ogi, T., and Greenberg, E. P. 2003. Identification, timing, and signal specificity of Pseudomonas aeruginosa quorum-controlled genes: A transcriptome analysis. J. Bacteriol. 185: 2066-2079

Seo, Y. S., Lim, J. Y., Park, J., Kim, S., Lee, H. H., Cheong, H., Kim, S. M., Moon, J. S., and Hwang, I. 2015. Comparative genome analysis of ricepathogenic Burkholderia provides insight into capacity to adapt to different environments and hosts. BMC Genomics 16:349.

Solis, R., Bertani, I., Degrassi, G., Devescovi, G., and Venturi, V. 2006. Involvement of quorum sensing and RpoS in rice seedling blight caused by Burkholderia plantarii. FEMS Microbiol. Lett. 259:106-112.

Staroń, A., Sofia, H. J., Dietrich, S., Ulrich, L. E., Liesegang, H., and Mascher, T. 2009. The third pillar of bacterial signal transduction: Classification of the extracytoplasmic function (ECF) sigma factor protein family. Mol. Microbiol. 74:557-581.

Steindler, L., Bertani, I., De Sordi, L., Schwager, S., Eberl, L., and Venturi, V. 2009. LasI/R and RhlI/R quorum sensing in a strain of Pseudomonas aeruginosa beneficial to plants. Appl. Environ. Microbiol. 75:5131-5140

Suárez-Moreno, Z. R., Caballero-Mellado, J., Coutinho, B. G., MendonçaPreviato, L., James, E. K., and Venturi, V. 2012. Common features of environmental and potentially beneficial plant-associated Burkholderia. Microb. Ecol. 63:249-266.

Suárez-Moreno, Z. R., Caballero-Mellado, J., and Venturi, V. 2008. The new group of non-pathogenic plant-associated nitrogen-fixing Burkholderia spp. shares a conserved quorum-sensing system, which is tightly regulated by the RsaL repressor. Microbiology 154:2048-2059.

Suárez-Moreno, Z. R., Devescovi, G., Myers, M., Hallack, L., MendonçaPreviato, L., Caballero-Mellado, J., and Venturi, V. 2010. Commonalities and differences in regulation of $\mathrm{N}$-acyl homoserine lactone quorum sensing in the beneficial plant-associated burkholderia species cluster. Appl. Environ. Microbiol. 76:4302-4317.

Teplitski, M., Mathesius, U., and Rumbaugh, K. P. 2011. Perception and degradation of $\mathrm{N}$-acyl homoserine lactone quorum sensing signals by mammalian and plant cells. Chem. Rev. 111:100-116.

Tettmann, B., Dötsch, A., Armant, O., Fjell, C. D., and Overhage, J. 2014. Knockout of extracytoplasmic function sigma factor ECF-10 affects stress resistance and biofilm formation in Pseudomonas putida KT2440. Appl. Environ. Microbiol. 80:4911-4919.

Theocharis, A., Bordiec, S., Fernandez, O., Paquis, S., Dhondt-Cordelier, S., Baillieul, F., Clément, C., and Barka, E. A. 2012. Burkholderia phytofirmans PsJN primes Vitis vinifera L. and confers a better tolerance to low nonfreezing temperatures. Mol. Plant-Microbe Interact. 25: 241-249.

Valvano, M. A., Keith, K. E., and Cardona, S. T. 2005. Survival and persistence of opportunistic Burkholderia species in host cells. Curr. Opin. Microbiol. 8:99-105.

Vejan, P., Abdullah, R., Khadiran, T., Ismail, S., and Nasrulhaq Boyce, A 2016. Role of plant growth promoting rhizobacteria in agricultural sustainability-A review. Molecules 21:573-590.

Ventre, I., Ledgham, F., Prima, V., Lazdunski, A., Foglino, M., and Sturgis, J. N. 2003. Dimerization of the quorum sensing regulator RhlR: Development of a method using EGFP fluorescence anisotropy. Mol. Microbiol. 48:187-198.

Venturi, V. 2006. Regulation of quorum sensing in Pseudomonas. FEMS Microbiol. Rev. 30:274-291.

von Rad, U., Klein, I., Dobrev, P. I., Kottova, J., Zazimalova, E., Fekete, A., Hartmann, A., Schmitt-Kopplin, P., and Durner, J. 2008. Response of Arabidopsis thaliana to $N$-hexanoyl-DL-homoserine-lactone, a bacterial quorum sensing molecule produced in the rhizosphere. Planta 229:73-85.

Walker, T. S., Bais, H. P., Déziel, E., Schweizer, H. P., Rahme, L. G., Fall, R., and Vivanco, J. M. 2004. Pseudomonas aeruginosa-plant root interactions. Pathogenicity, biofilm formation, and root exudation. Plant Physiol. 134:320-331.

Whitehead, N. A., Barnard, A. M., Slater, H., Simpson, N. J., and Salmond, G. P. 2001. Quorum-sensing in Gram-negative bacteria. FEMS Microbiol. Rev. 25:365-404.

Wongtrakoongate, P., Tumapa, S., and Tungpradabkul, S. 2012. Regulation of a quorum sensing system by stationary phase sigma factor RpoS and their co-regulation of target genes in Burkholderia pseudomallei. Microbiol. Immunol. 56:281-294.

Zúñiga, A., Poupin, M. J., Donoso, R., Ledger, T., Guiliani, N., Gutiérrez, R. A., and González, B. 2013. Quorum sensing and indole-3-acetic acid degradation play a role in colonization and plant growth promotion of Arabidopsis thaliana by Burkholderia phytofirmans PsJN. Mol. Plant-Microbe Interact. 26:546-553. 